\title{
Design of Concrete Tunnel Linings for Fire Safety
}

Chrysanthos Maraveas, Technical Director; Apostolos A. Vrakas, Civil Eng.; C. Maraveas Partnership, Athens, Greece.

Contact: c.maraveas@maraveas.gr

DOI: $10.2749 / 101686614 X 13830790993041$

\begin{abstract}
This paper provides an overview of some significant aspects concerning the design of concrete tunnel linings subjected to severe fire exposure. The distinguishing feature of tunnel fires is the possible rapid rise of the air temperature within few minutes. The factors that contribute to this phenomenon in combination with the fire duration and the fire spread along the longitudinal direction are cited. Additionally, the widely used fire curves are presented, showing their influence on the predicted temperature profile of a concrete cross-section through uncoupled heat transfer transient numerical analyses. Then, the effect of fire on the concrete behaviour is briefly described with examples from real fire accidents. The focus is on the explosive spalling of concrete, provided that, in general, tunnels are at greater risk than other structures, principally due to the high heating rate and the high initial moisture content. The main features and mechanisms of spalling are presented in conjunction with the available modelling techniques and the design approaches against spalling. Finally, the effectiveness of several passive protection measures is discussed, based on the recent experiences.
\end{abstract}

Keywords: concrete; fire; passive protection measures; spalling; time-temperature curves; tunnel linings.

\section{Introduction}

Numerous catastrophic tunnel fire events have occurred during the past decades, increasing the interest in structural fire safety of underground facilities. Detailed summaries of road and rail tunnel fire incidents can be found in the literature, ${ }^{1-4}$ clearly highlighting the importance of factoring fire risk in the design of tunnels. Although fires in road tunnels are more frequent, the number of fatalities during fires in railway systems generally seems to be far greater. ${ }^{1}$ However, apart from fatalities, injuries and property loss, a prolonged disruption of operations may occur, mainly due to considerable structural damage of the lining.

The special feature that distinguishes tunnel fires from the ordinary ones (e.g., those that occur in buildings) is the sharp rise of the ceiling gas temperature, often in excess of $1000^{\circ} \mathrm{C}$, within few minutes. This phenomenon affects both the fire suppression (rendering a rapid extinguishing almost impossible) and the structural integ-

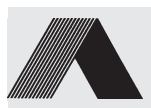

Peer-reviewed by international experts and accepted for publication by SEI Editorial Board

Paper received: June 27, 2013

Paper accepted: August 30, 2013 rity of the tunnel lining (favouring the explosive spalling) of normal strength concrete (NSC) and high strength concrete (HSC). Consequently, a wide range of detection devices and active or passive protection measures are currently installed in tunnels worldwide. The experience gained from large fire events with several detrimental effects, for example, in the Channel (1996, England-France, rail tunnel), ${ }^{1,5}$ the Mont Blanc (1999, France-Italy, road tunnel), ${ }^{1,6}$ the Tauern (1999, Austria, road tunnel $)^{6,7}$ and the St. Gotthard (2001, Switzerland, road tunnel $)^{1,6}$ tunnels, in combination with full-scale experiments within the framework of extensive research projects for tunnel fire safety in response to these accidents (e.g., DARTS, FIT, UPTUN, Safe Tunnel, SIRTAKI, Virtual Fires, Safe-T, L-SURF) ${ }^{1}$ have provided invaluable knowledge for a more foresighted and effective planning of underground space, and demonstrated the significance of fire safety management in tunnels.

The present study focuses on the structural part, providing a general overview of some significant aspects with respect to the design of concrete tunnel linings subjected to severe fire exposure. Initially, the main tunnel fire characteristics and the widely used timetemperature curves are presented.
Subsequently, the effect of fire on the concrete behaviour is described with due attention to the phenomenon of explosive spalling. Its main features and mechanisms are presented in conjunction with the available modelling methods and design approaches for fire safety of tunnels (few code provisions exist). Examples from real fire accidents are included to demonstrate the possible fire-induced damage of the tunnel structure. Finally, several passive protection measures are examined for their effectiveness, advantages and drawbacks.

\section{Fire Characteristics and Fire Curves}

\section{Fire Characteristics}

The tunnel fires are peculiar due to the characteristics of burning fuel and vehicles with high calorific potential in combination with the confinement of the heat released. The increase in serious road tunnel fire accidents is closely related to the increase in the traffic of heavy goods vehicles on the highways, while even non-hazardous materials may become dangerous when burned in a confined space, see for example, flour and margarine in the Mont Blanc or tyres in the Gotthard tunnel fire. ${ }^{6}$ The combination of the aforementioned features can lead to remarkably high heat release rates (HRR) and gas temperatures, as well as long fire duration. The highest thermal impact appears normally at the top of the tunnel (ceiling), owing to the direct flame impingement, and becomes smaller at the benches. ${ }^{8}$

Apart from real tunnel accidents including the well-known cases that are referred to in the introductory section, wide knowledge has been obtained by means of large-scale fire tests. A detailed review of the extensive research projects can be found in the well-known handbook of tunnel fire safety ${ }^{1}$; however, special mention should be made of the Runehamar fire tests (Norway, 2003, under the aegis of the UPTUN project) ${ }^{4,8,9}$ that have provided valuable information with 
respect to several factors related to tunnel fires.

Five different mechanisms of fire spread in a tunnel are generally considered $^{10,11}$ : (a) flame impingement; (b) flame spread; (c) remote/spontaneous ignition; (d) fuel transfer and (e) explosion, which indicate its severity. Smoke and toxic gases emitted from the burning materials can greatly reduce the visibility and subsequently impede both evacuation and fire-fighting. Therefore, sufficient ventilation capacity is one of the most important issues in tunnel fire safety, affecting the HRR, the fire size and the spread, as well as the smoke control. Extensive reviews ${ }^{1}$ and studies based upon model, ${ }^{12}$ mid-scale ${ }^{13}$ and large-scale tunnel fire tests ${ }^{9,11,14}$ are available in the literature on this topic.

In general, the ventilation systems can be either natural or mechanical (forced). The latter systems contain longitudinal and transverse (fully-, semi- or exhaust semi-transverse) configurations that involve several components such as fans, ducts and dampers to control the air movement. Practically, the ventilation velocity should be greater than the minimum air velocity required for the suppression of the smoke spreading against the longitudinal ventilation flow under fire conditions (smoke reverse flow) preventing back-layering, which means that the tunnel is free of smoke upstream of the fire site. ${ }^{15}$ This minimum velocity is referred to as the critical ventilation velocity.

It becomes apparent that a tunnel fire gives rise to complex three-dimensional phenomena that are influenced by the HRR (and thus by the combustible sources), the ventilation system and the tunnel geometry. The transfer of heat within the tunnel can be assessed using the computational fluid dynamics (CFD) modelling, ${ }^{1}$ which apart from a trustworthy simulation of the smoke flow propagation, provides a means to visualize, understand and interpret the phenomena that cannot be easily observed or measured. Its greatest disadvantage is the high computational cost; however, hybrid (multiscale) models have been developed to handle this problem. ${ }^{16}$ In particular, they decrease the required time of a pure three-dimensional simulation without significant loss of accuracy by combining the three-dimensional models (for the area close to the seat of the fire) with the one-dimensional ones (for the regions away from the fire). Several experimental results have been used for the verification or even the calibration of CFD models for further studies. ${ }^{17,18}$ Besides these sophisticated field models, some fire zone ${ }^{19}$ and empirical models ${ }^{20}$ are widely used. The latter models are expressed via analytical relationships (derived from the evaluation of fire tests) and estimate the maximum ceiling gas temperature taking into account various relevant parameters as have been listed above (e.g., HRR, tunnel geometry and ventilation conditions). Nevertheless, the fire curves, presented in the next subsection, still remain the most common approach in engineering practice. The assessment of the thermal response is fundamental with respect to the evaluation of the overall stability and safety of a structure. More specifically, after the determination of the temperature distribution within the lining using the corresponding temperaturedependent thermal properties (density, conductivity and specific heat), the structural performance can be calculated based upon the modified mechanical properties. Furthermore, performance-based design alternatives (accounting for different fire scenarios, material properties, loading conditions and so on) would allow for a higher flexibility of design, providing a better understanding of the behaviour of the structure. ${ }^{21}$

\section{Fire Curves}

Various time-temperature curves have been proposed. The most popular of them, ${ }^{4,8,22,23}$ related to tunnel design, are as follows (Fig. 1):

(1) ISO 834 standard fire curve $e^{24,25}$ : This cellulosic curve is widely used in fire testing of structural elements. It applies to materials found in typical buildings and thus is adequate for the estimation of the thermal response of corresponding members such as beams, columns and slabs. It was used for many years for tunnels, but proved inadequate for highly combustible materials, ${ }^{4}$ as will be verified in the following.

(2) ASTM E119 fire curve ${ }^{26}$ : This curve is similar to the ISO timetemperature curve involving a continuously increasing furnace temperature (with decreasing rate), thereby being, again, unsuitable for highly combustible materials.

(3) HC (Hydrocarbon) fire curve $e^{25}$ : The hydrocarbon curve applies to hazardous materials, for example, fuels and chemicals, including those for petrochemical industries. In opposition to the previous cases, it provides a rapid increase of the air temperature within the first few minutes reaching its maximum value after half an hour.

(4) HCM (Hydrocarbon modified) or $H_{\text {inc }}$ (Hydrocarbon increased) fire curve ${ }^{27}$ : This raised hydrocarbon curve was initially proposed in France, representing a more severe scenario with rapid and complete combustion of the hazardous materials. It is approximately derived from the original $\mathrm{HC}$ curve by multiplying the

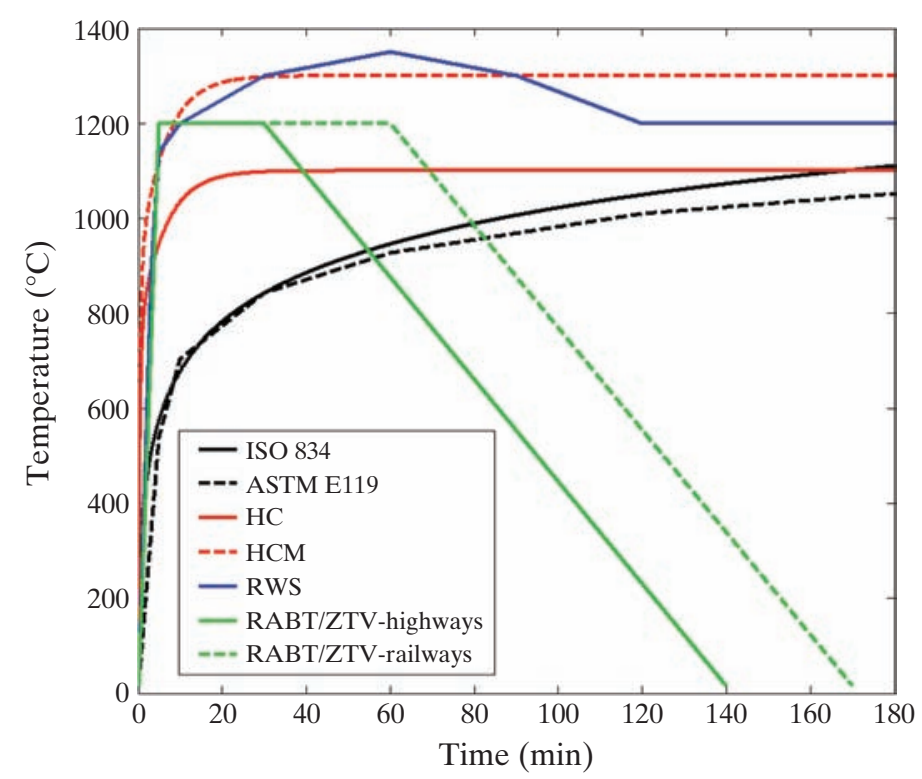

Fig. 1: Characteristic time-temperature (fire) curves for tunnels 
corresponding temperatures by a factor of 1300/1100 (the exact relationship slightly differs in order for both curves to give the same initial temperature, that is, $T=$ $20^{\circ} \mathrm{C}$, at $t=0 \mathrm{~min}$ ). The maximum developed temperature is $1300^{\circ} \mathrm{C}$ instead of $1100^{\circ} \mathrm{C}$ (Fig. 1).

(5) RWS (Rijkswaterstaat) fire curve: This curve was developed in the Netherlands exclusively for the design of tunnels, after laboratory testing. It presents a small temperature reduction after $60 \mathrm{~min}$ of fire exposure (Fig. 1), but there is no cooling branch similarly to the previous curves.

(6) RABT/ZTV fire curves: Under the German regulations, there are separate fire curves for highway and railway tunnels. The latter one implies an extension of the plateau for $30 \mathrm{~min}$, while both of them provide a linearly descending (cooling) phase of $110 \mathrm{~min}$ (Fig. 1).

The World Road Association $(\mathrm{PIARC})^{28}$ in cooperation with the International Tunnelling Association (ITA $)^{8}$ have provided recommendations with respect to the selection of the appropriate fire curve. According to the type of traffic (cars/vans vs. trucks/tankers) and the consequences of the structural failure due to fire, the use of either the ISO 834 or the RWS/ $\mathrm{HCM}$ curve is proposed (with the corresponding fire duration), both for the main and the secondary structures.

\section{Thermal Analysis of a Cross-Section}

The influence of the aforementioned fire curves on the developed temperatures in an unprotected reinforced concrete section is examined through mere uncoupled heat transfer transient finite element analyses. ${ }^{29}$ A 600-mm deep and 150-mm wide rectangular cross-section reinforced with three $16-\mathrm{mm}$ steel bars is considered, assuming a cover depth of $45 \mathrm{~mm}$ (Fig. 2a). Two-dimensional heat transfer elements (four-node linear elements with a nodal temperature degree of freedom) are used for estimating the thermal response of the concrete section. A convection coefficient of $50 \mathrm{~W} / \mathrm{m}^{2} \mathrm{~K}$ in conjunction with a radiation emissivity of 0,5 is assumed for the exposed surface, while the convection coefficient for the unexposed surface is taken as $9 \mathrm{~W} / \mathrm{m}^{2} \mathrm{~K}$ neglecting heat flow due to radiation, according to EC 1-1.2. ${ }^{25}$ The heat is applied to the bottom surface of the section, while no heat is transferred normal to the vertical surfaces (adiabatic conditions). The specific heat (assuming a moisture content of $3 \%$ for the concrete) as well the thermal conductivity (considering the upper limit for the concrete) of concrete and steel are calculated according to EC 2-1.2. ${ }^{30}$ Their densities are (a)

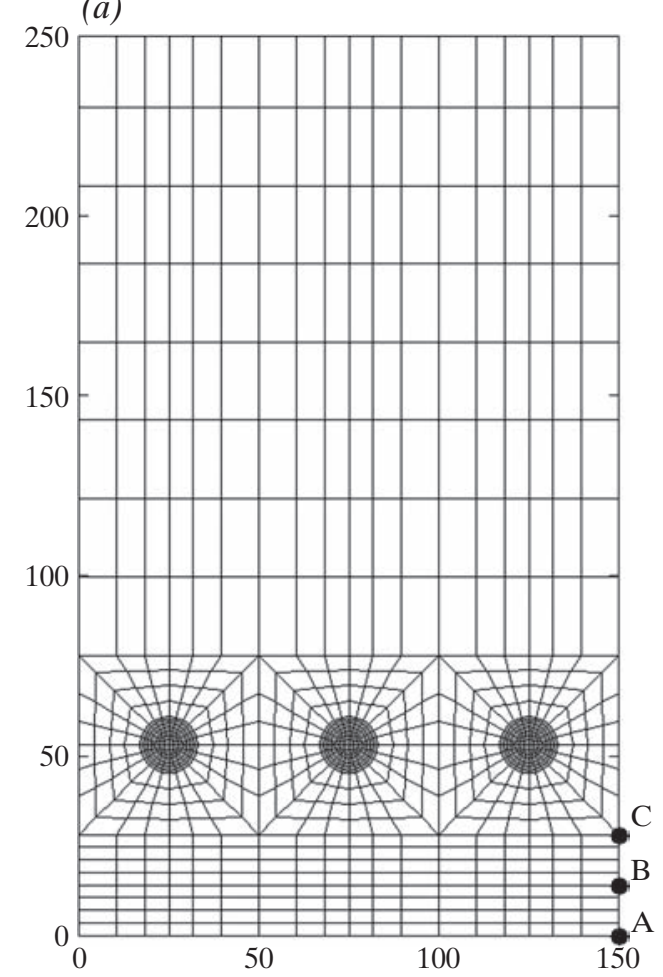

(b)

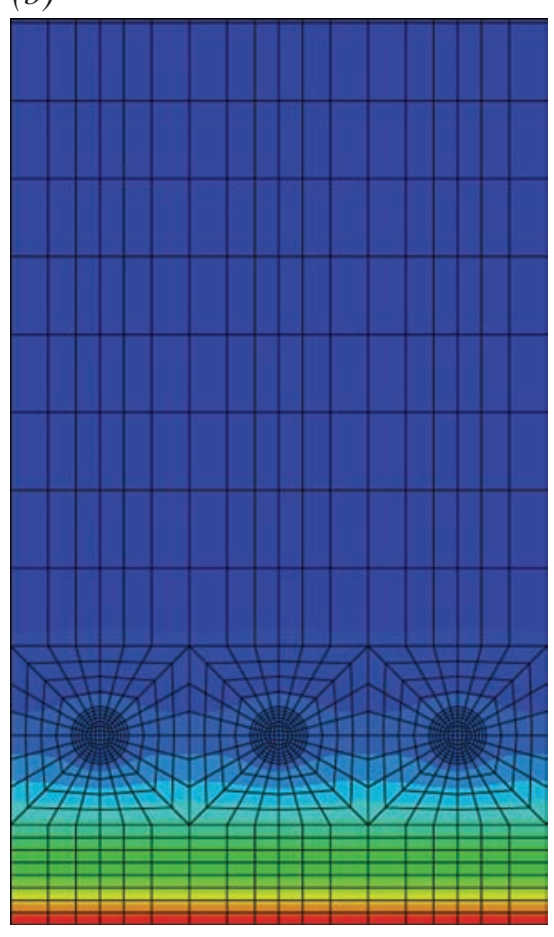

Fig. 2: (a) Finite element model (cut of the cross-section at the depth of $250 \mathrm{~mm}$ ) and (b) temperature profile after $30 \mathrm{~min}$ of fire exposure according to the HCM curve (cf. Fig. $4 \mathrm{c}$ ) taken as $2300 \mathrm{~kg} / \mathrm{m}^{3}$ and $7850 \mathrm{~kg} / \mathrm{m}^{3}$, respectively.

The thermal analyses results are presented in Figs. 3 and 4. Figure 3 shows the time-temperature curves for points A, B and C (cf. Fig. $2 a$ for their location and Fig. $2 b$ for a temperature contour of the finite element model), whereas Fig. 4 illustrates the temperature distribution at the depth of the section for different fire exposure times (5, 10 and $30 \mathrm{~min}$ ). The high heating rate of the fire curves (3)-(6) leads to steep temperature gradients close to the bottom surface (to a depth of about 30 $\mathrm{mm}$ ), which in turn will cause a thermal shock to the surrounding concrete. More specifically, temperatures above $800^{\circ} \mathrm{C}$ appear within the first 10 min of fire exposure. These indicative numerical predictions have also been observed in experimental studies (e.g. Ref. [31]). On the other hand, the cellulosic curves (1) and (2) cannot produce such high temperatures.

The temperature field is of crucial importance with respect to the structural safety of the lining, due to the consequent degradation of the mechanical properties of its components. However, the reliability of the present thermal response requires the maintenance of the concrete integrity (as well as the use of no protection measures). As will be thoroughly described in the subsequent sections, spalling is a common phenomenon occurring in concrete members under severe fire exposure that causes a successive loss of material (Fig. 5a). As a result, the corresponding temperatures at the depth of the section will exhibit a sharp increase as the concrete is gradually scaled off. After the removal of the entire concrete cover, the steel bars will be no longer insulated (Fig. 5a), consequently losing in a short time both their strength and stiffness.

Ultimately, it is obvious from the results of these indicative thermal analyses that the design of a structural member for fire safety depends on the selection of the time-temperature curve, which may not be representative of the occurring situation, especially in tunnels, where a wide range of factors affect the size, the growth and the duration of fire.

\section{Concrete Behaviour in Fire}

\section{General Properties}

Concrete neither burns nor emits any toxic fumes or smoke when exposed 

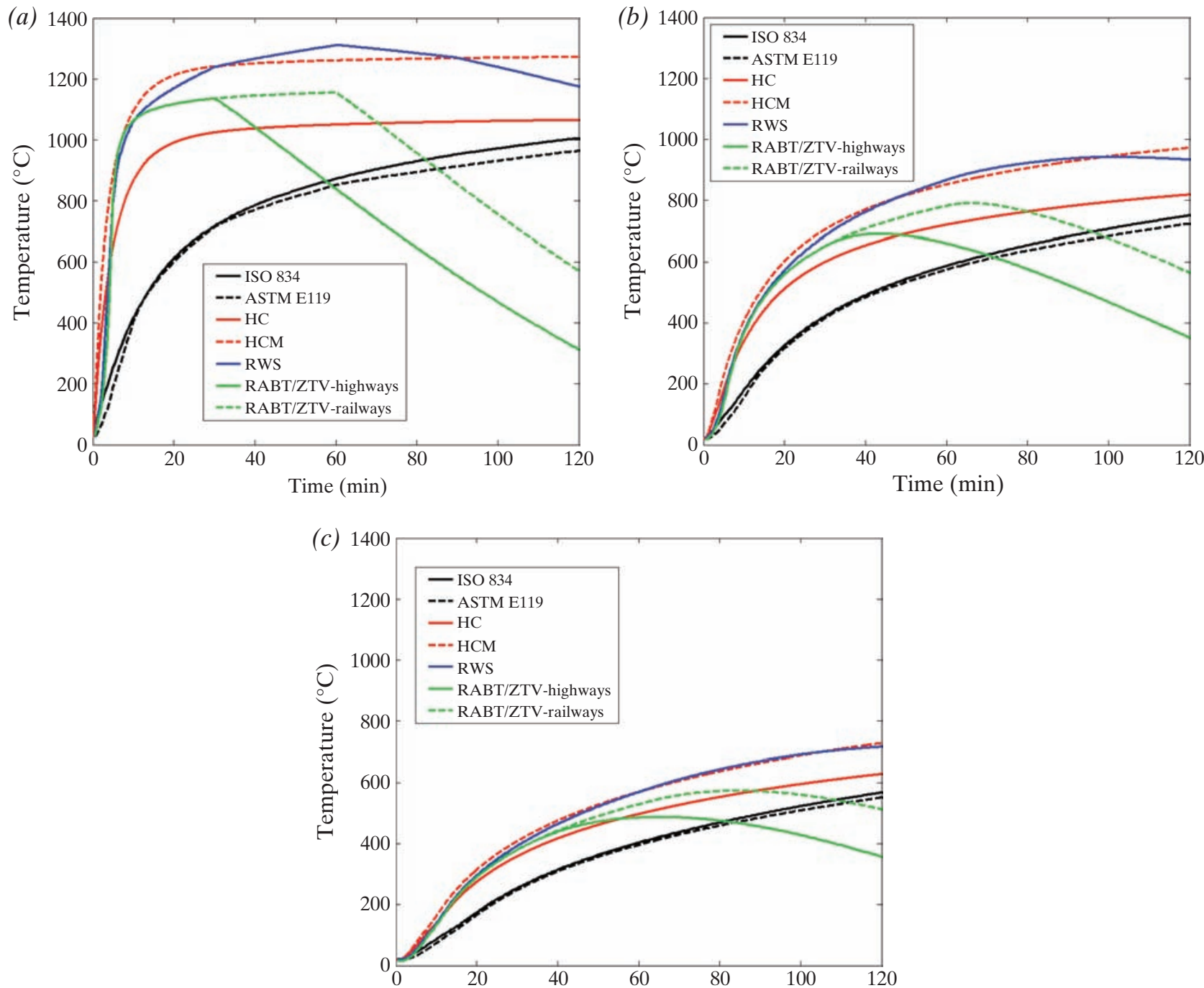

Fig. 3: Time-temperature curves at (a) point $A,(b)$ point $B$ and (c) point $C$

to fire, offering a high degree of fire resistance. Additionally, the slow rate of heat transfer (low thermal conductivity) enables concrete to act as an effective fire shield. This excellent performance is due to the main constituents of its mixture, namely cement and aggregates. Both material and structural behaviour of concrete are well described in the literature. ${ }^{21,23,32-34}$ However, a brief overview is presented in the following sections for completeness.

\section{Material Behaviour}

Concerning the material behaviour of concrete at elevated temperatures, an irreversible loss of stiffness and strength takes place, which is referred to as thermal damage (or softening) and thermal decohesion, respectively. ${ }^{32,35}$ As a result, the elastic (Young's) modulus and the compressive and tensile strength can be expressed with respect to the temperature, constituting temperature-dependent variables. Several relations and curves (either prescriptive-codified ${ }^{30}$ or experimental ${ }^{32}$ ) have been proposed not only for concrete, but also for the steel reinforcement. When exposed to high temperature, the chemical composition and physical structure of concrete change considerably. Microstructural analysis of firedamaged concrete has shown that both thermal damage and decohesion result from the dehydration of concrete on the microlevel, while the cement paste, the type of aggregates and the water content affect the overall response to a large degree. ${ }^{32,35}$

\section{Structural Behaviour}

Concerning the structural behaviour of concrete exposed to high temperatures, it may be characterized by spalling (depending on various factors, summarized in the section on Explosive Spalling), where pieces of concrete fall off the surface of a structural element (Fig. 5a). Several types of spalling are defined in the literature. ${ }^{23,33,36,37} \mathrm{An}$ instructive approach is to consider the location of its occurrence and its origin. ${ }^{38}$. Depending on the first factor, spalling can be divided into three categories, namely, aggregate, corner ( $c f$., e.g., beams and columns) and surface spalling; while depending on the second factor, it can be divided into two categories, namely, progressive and explosive spalling. Explosive spalling is the most violent form of spalling, which may be encountered in tunnels because of the special fire characteristics as described in the section on Fire Characteristics and Fire Curves. In particular, recent tunnel accidents have shown that it constitutes the main reason for significant structural damage to the concrete linings, and therefore it will be further analysed.

\section{Explosive Spalling}

The main feature of explosive spalling is the burst-out of concrete pieces accompanied by sudden release of energy and loud sounds. Numerous factors affect the explosive spalling of concrete and are summarized in the 

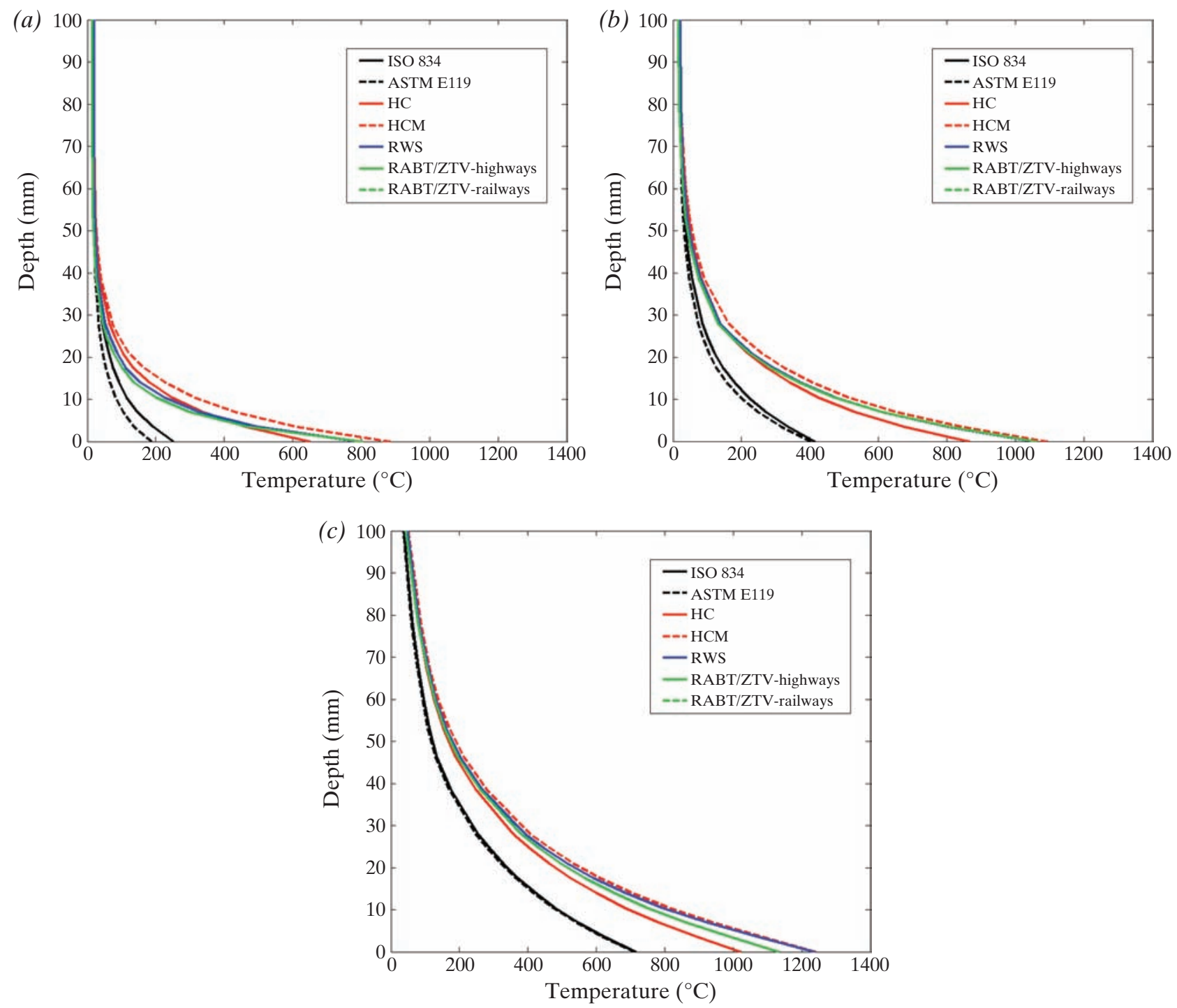

Fig. 4: Temperature distribution at the depth of the cross-section after (a) $t=5 \mathrm{~min},(b) t=10 \mathrm{~min}$ and (c) $t=30$ min of fire exposure

(a)

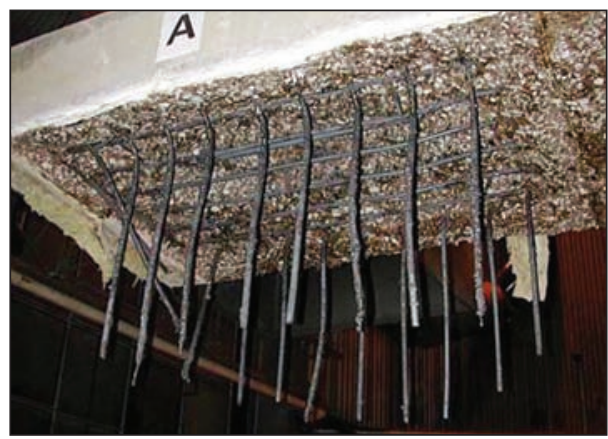

(b)

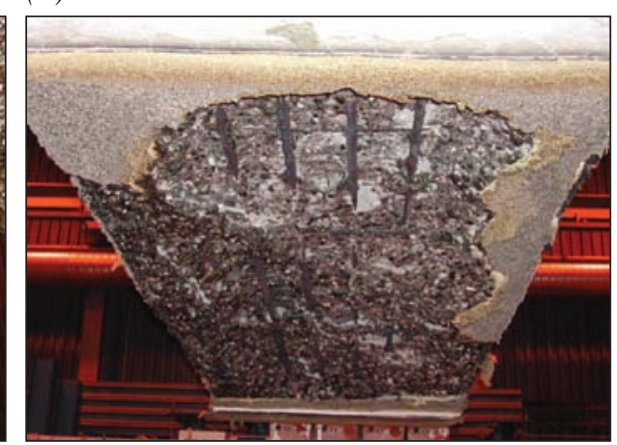

Fig. 5: (a) Specimen of tunnel concrete after fire exposure - occurence of severe spalling (spalling depth of $300 \mathrm{~mm}$ ) and (b) specimen of tunnel concrete where the thermal barrier fell off during the fire test $t^{31}$

following list, while a thorough commentary on each one of them can be found in the literature $23,33,36,39$ :

- Heating rate

- Heating profile

- Section size

- Section shape

- Moisture content

- Pore pressures
- Concrete permeability

- Concrete age

- Concrete strength

- Compressive stress before and during heating

- Restraint to thermal expansion

- Aggregate type

- Aggregate size

- Cracking

- Reinforcement
- Cover to reinforcement

- Supplementary reinforcement

- Polypropylene fibres

- Steel (and/or others, e.g., nylon) fibres

- Air entrainment

Two main mechanisms are considered for the explanation of this phenomenon $^{21,33,35,36}$ : the hydraulic and the thermal spalling. The first is attributed to the low permeability of concrete, especially in combination with high moisture content, resulting in a pore pressure build-up (tensile stresses) The second is caused by the restrained thermal dilation of the region close to the heated surface by the cooler inner concrete, leading to high compressive stresses parallel to it. Additionally, a combination of the above mechanisms has been proposed, ${ }^{21,33,36}$ whereas the external loading is of great importance in any approach.

High and ultra high strength concrete (HSC and UHSC, respectively), which are mainly used in case of prefabri- 
cated elements, are more susceptible to explosive spalling than the NSC, which is used in case of in situ lining or shotcrete. ${ }^{36}$ In spite of the high strength and good durability, their low permeability acts as a disadvantage at high temperatures. It should be noted that some doubts over the credibility of this deduction have been expressed, ${ }^{40}$ according to which the effect of low permeability may be balanced by the effect of high splitting tensile strength.

The available standards for the protection of structures against spalling are insufficient. For instance, EC 2-1.2 requires no specific check for spalling if (a) the moisture content of the concrete is less than $3 \%$ by weight (otherwise a more accurate assessment of moisture content, type of aggregate, permeability of concrete and heating rate should be considered) or (b) the tabulated data are used to prescribe generic fire ratings for concrete members (except for axis distances greater than $70 \mathrm{~mm}$ ). Considering spalling in tunnel linings, PIARC ${ }^{28}$ and ITA $^{8}$ have proposed some guidelines with respect to the fire resistance for road tunnels, however, without providing certain technical details, while RWS (the Directorate-General of Public Works and Water Management in the Netherlands) $)^{41}$ have specified some performance criteria for under water tunnels.

Nevertheless, extensive experimental and theoretical investigations have led to a rich stream of knowledge and experience, although these need to be depicted as robust prescriptive requirements. Therefore, some general remarks concerning concrete spalling can be made according to Ref. [36]. More specifically, medium concrete sections as well as NSC members with moisture content higher than $3 \%$ by weight are more susceptible to spalling. Moreover, the likelihood of explosive spalling increases with increase in the heating rate, with applied loads, higher concrete strength and thermal expansion. Finally, explosive spalling takes place within the first $40 \mathrm{~min}$, otherwise it is unlikely to occur.

\section{Modelling of Concrete and Tunnel Structures}

The estimation of concrete response to fire constitutes a complex problem that in general requires fully coupled thermo-hydro-mechanical modelling. Several aspects have to be incorporated into the analysis: inter alia the temperature field, the vapour pressure, the moisture transport, the material degradation and the mechanical damage. Numerous models ${ }^{32,42,43}$ have been proposed for the assessment of concrete behaviour at elevated temperatures based on the mechanics of multiphase porous media (concrete consists of solid, liquid (water) and gaseous (water vapour and dry air) phases). However, no existing model can accurately predict the spalling risk. Until now, there are no theoretical tools available to predict the probability and amount of spalling, while its prediction during heating has been largely an imprecise empirical exercise. $^{23,33}$

Concerning the analysis of tunnel structures, several approaches, more or less sophisticated, have been proposed, that are mainly based on the finite element method. The simplest models simulate the ground around the tunnel using plane strain (for the ground) and plane strain or plane stress (for the lining) elements, accounting for the ground-structure interaction and the temperatureinduced loss of structural stiffness. ${ }^{44}$ The discretization across the lining thickness requires that bending moments can be derived from the stress analysis. The temperature penetration into concrete is determined by means of a heat transfer analysis, considering appropriate temperaturedependent thermal properties ( $c f$. the section on Fire Characteristics and Fire Curves); however, it becomes more complicated in the presence of spalling. Specifically, the thermal response of a spalled concrete member is generally underestimated to a large degree ${ }^{45}$ (i.e., the predicted temperatures are much lower than the expected ones), which in turn provides an overestimated structural capacity. This problem can be addressed by incorporating a temperature-dependent removal of finite elements, ${ }^{45}$ accounting for surface temperatures, which indicate the occurrence of spalling in NSC and HSC based upon experimental results (usually in the range of $350-450^{\circ} \mathrm{C}$ ). Specifically, once the developed surface temperature reaches the predefined critical level, a concrete layer of certain thickness is removed. The heating process continues until the temperature of the current surface becomes equal to the critical one, the next concrete layer is removed, and so on. Afterwards, the thermal analysis may be followed by a mechanical (static) analysis to evaluate the structural performance of the considered element. In the framework of two-dimensional (commonly plane strain) finite element modelling, some more advanced studies have been carried out. ${ }^{46,47}$ Particularly, both the temperature and the dehydration degree fields are determined by means of a chemo-thermal analysis. The obtained results serve as input for the subsequent chemo-mechanical analysis, providing insight into the deformation and stress state of the lining. An approximate estimation of the spalling depth can be obtained from the plastic strain profiles in the radial direction.

Another procedure is based on the layer approach. ${ }^{48}$ The lining section is divided into layers at its depth (considering both concrete and reinforcement, Figs. $6 a$ and $6 b$, respectively), and after the determination of the thermal profile (usually by means of heat transfer analysis as mentioned previously), the structural response of the entire system is calculated within the "beam-spring" concept (Fig. 6c) The global structural model for the lining includes ground-structure interaction since the tunnel lining is modelled through layered beam finite elements, whereas the ground is modelled using compression-only spring elements of appropriate stiffness. The layer approach enables the consideration (a) of spalling of the tunnel structure by deactivation of the respective layers at the inner side of the lining and (b) of assignment of temperature-dependent material parameters of concrete and steel reinforcement to the remaining layers. $^{49-51}$

Furthermore, advanced models that cope with the thermal fluid-structural coupling have been presented recently, considering a multiphase porous material for the simulation of concrete at high temperatures. ${ }^{52}$ These models go a step forward from previous simulations, where the calculated thermal fluxes were used as input for the analysis of the concrete structure. ${ }^{53}$ However, these models are not suitable for practical engineering design purposes.

\section{Consequences of Fire on the Concrete Lining}

Damage to the concrete tunnel lining when heated is mainly caused by dehydration, which leads to loss of 
(a)

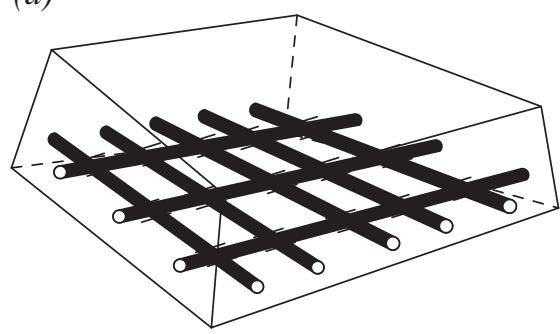

(b)

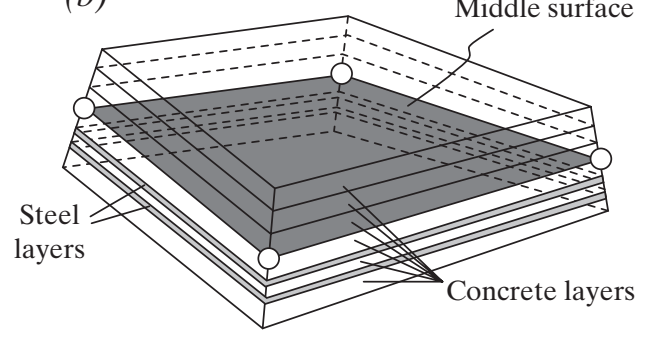

(c)

Ground surface

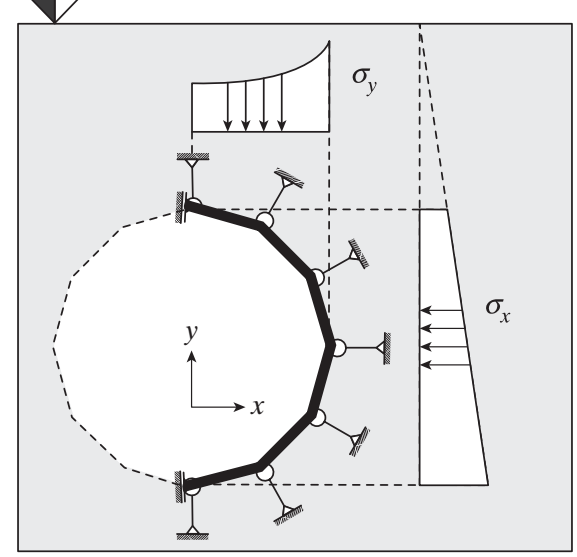

Fig. 6: Consideration of reinforcement within the layer concept: (a) real situation and (b) consideration of reinforcement by steel layers; (c) illustration of the "beam-spring" model $^{49}$ strength and stiffness, as well as by possible spalling, as has already been mentioned. The condensation of smoke on the tunnel wall, the ceiling and the operational installations causes further impairment. It is always regarded that the tunnel cannot be operated for a considerable period of time, until the necessary remedial works are accomplished, including apart from the civil engineering repairs, the electromechanical ones. Despite the fact that even severe fires have not led to an entire collapse of the tunnel crosssection, the damage to the equipment and to the secondary structures, the disruption of service, the difficult conditions of repair and the large quantities of materials required increase the economic cost. For instance, in the which was the closest to an actual collapse, 680 tons of plain shotcrete and 630 tons of fibre-reinforced shotcrete were used for the replacement of the damaged lining concrete. ${ }^{5}$ Specifically, the 450-mm thickness of the HSC precast lining segments with compressive strength of $80-100 \mathrm{MPa}$ was reduced by $100-200 \mathrm{~mm} .^{46}$

The effects of such intense tunnel fires on the concrete lining depend on the material constituents and their quality, as well as the moisture content and the loading conditions that also extreme case of the Channel tunnel, depend on the form of the tunnel. ${ }^{21,54}$ In circular and horseshoe tunnels (Fig. 7), the principal load is compression in the circumferential direction. The imposed constraints in both the longitudinal and the circumferential directions (the colder parts of the lining resist the expansion of the inner heated ones) may lead to higher compressive stresses during fire exposure, which increase the spalling risk. A critical condition is reached within the wall thickness, where a stress peak arises as a result of the stress relaxation of the most exposed layer and the deformation constraint exerted by the cold extrados $^{54}$ (Fig. 7). However, they usually have ample capacity for the actual service load, and as a result they can sustain significant damage, including concrete spalling. If the conditions for activating a collapse mechanism are not met, the contour of the tube section is slightly affected by the thermal strain and no significant change in the interaction with the surrounding ground is expected. ${ }^{54}$ It should be noted that in case of segmental linings, the deterioration of the flexural stiffness of the joints may affect the overall structural behaviour of the lining rings and determine the failure pattern. ${ }^{55,56}$ On the other hand, the rectangular tunnels of the cut-and-cover type present different behaviour. The moment action is more pronounced, and sagging of the roof due to overheating of the steel reinforcement is a possible failure mechanism. ${ }^{54}$ This can generally be prevented by increasing the lining thickness, which is often limited.

Another important issue related to real tunnel accidents concerns the investigations for assessing the damage to the concrete lining with the objective of determining the need for repairs (from the identification of burnt concrete to the measurement of concrete thickness and so on). A comprehensive review for the existing assessment methods of fire damage to concrete tunnel linings,
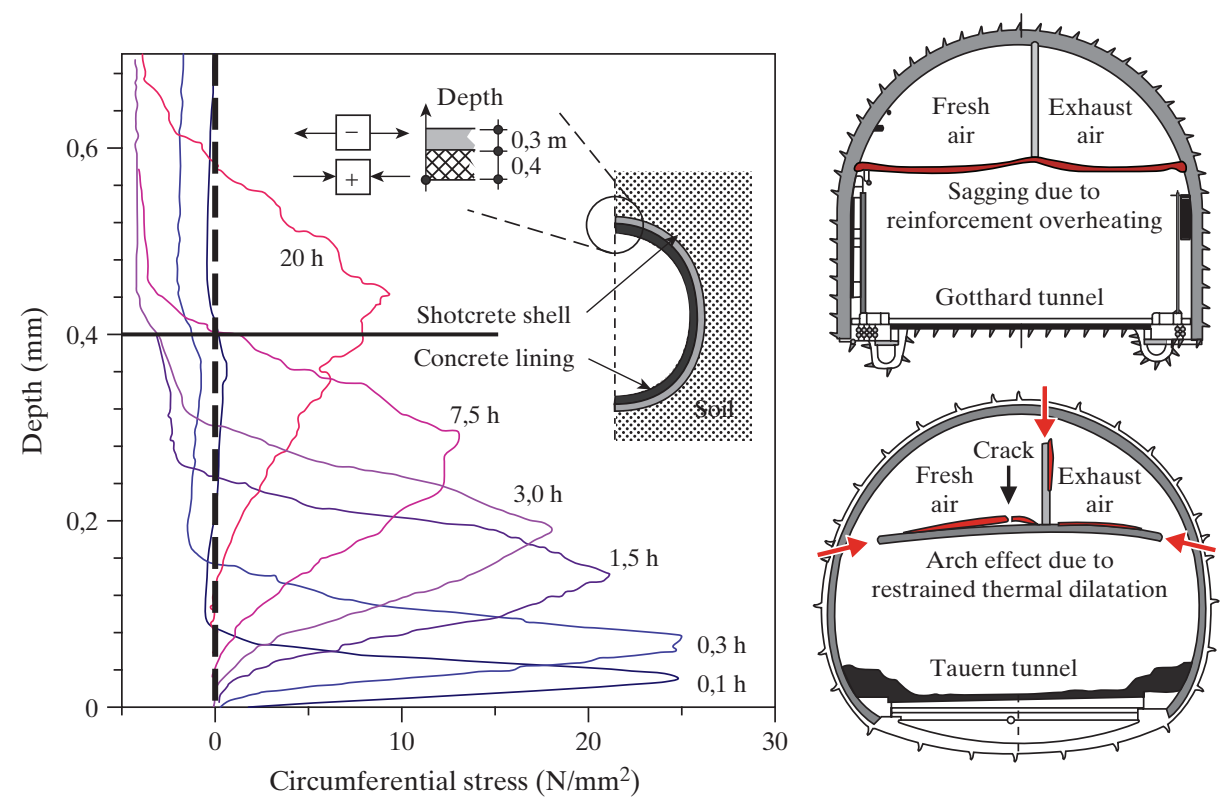

Fig. 7: Circumferential stress in the lining of a circular tunnel under fire at different times, and collapse mechanisms in the false ceilings separating the ventilation ducts ${ }^{54}$ 

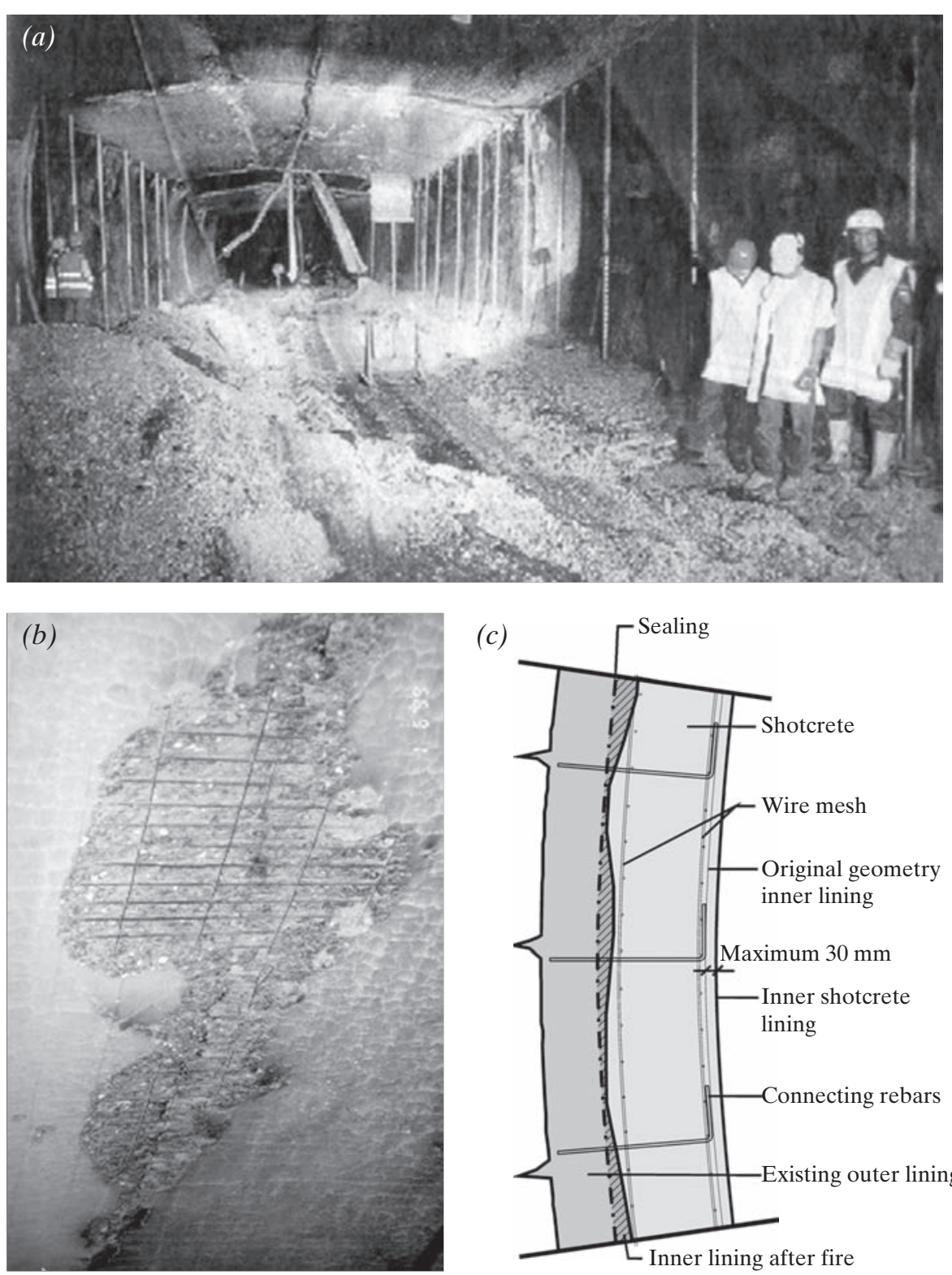

(c)

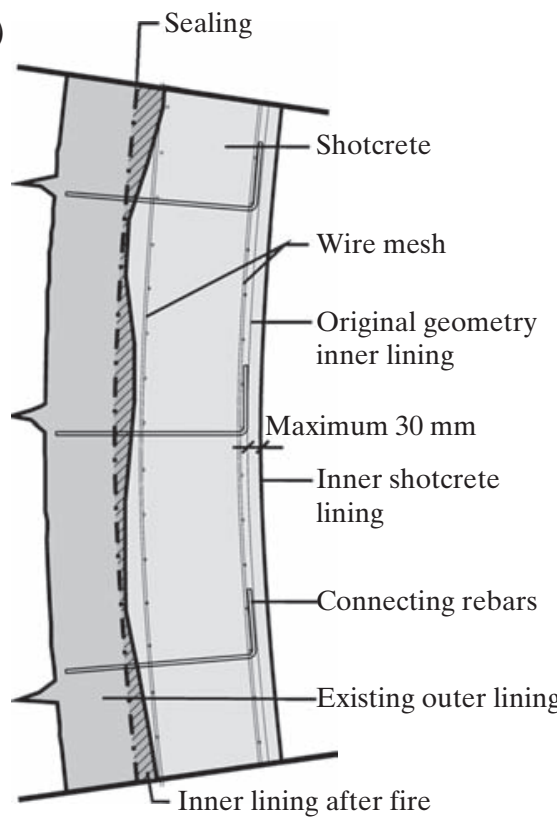

Fig. 8: Tauern tunnel (1999, Austria): (a) a view of the damaged tunnel interior, (b) spalling of the reinforced concrete on the bottom of the ceiling and (c) remedial work for the inner lining ${ }^{7}$

pointing out their main features and limitations has also been carried out. ${ }^{54}$

Finally, the damages to tunnels can as an example be illustrated by the observed structural damages in the case of the Tauern tunnel, ${ }^{7}$ which constitutes a characteristic example of severe tunnel fire accident. Long parts of the ceiling (up to $6 \mathrm{~m}$ ) were detached and spalled concrete from the side walls all over the pavement was observed (Figs. $8 a$ and $8 b$ ). Moreover, the unreinforced concrete of the inner lining spalled to a maximum depth of $400 \mathrm{~mm}$ over a 100-m tunnel length in the area of the highest temperatures. Adjacent to this area, there was spalling of $50 \mathrm{~mm}$ over the complete side wall surface or locally over another $450 \mathrm{~m}$ of tunnel length. Lastly, about $600 \mathrm{~m}^{3}$ of chip-size spalled concrete following, the available passive protection measures are presented, after an initial brief reference to the active systems.

To be suitable for consideration for use in tunnels, a suppression system must be able to control fire growth within acceptable parameters and to prevent spread to adjacent vehicles. It should limit the growth of a fire by pre-wetting adjacent combustibles, controlling ceiling gas temperatures to prevent structural damage and providing the possibility of manual fire-fighting. ${ }^{1}$ Water mist systems and sprinklers have proved to be effective in mitigating the effects of tunnel fires. Reference is made to the existing literature ${ }^{1,57}$ for information about active mitigation measures against fire.

On the other hand, several passive protection measures have been proposed for the avoidance of concrete explosive spalling that are currently adopted in the design of new tunnels. First of all, the concrete quality constitutes a factor which may ensure the integrity of a structural member. Nowadays, it is quite possible to manufacture concrete with qualities that have very little probability of spalling even if the moisture content is relatively high and the structure is loaded moderately in compression. ${ }^{31}$ Furthermore, fire resistance depends among others on the shape and thickness of the structural members as well as on the layout of the reinforcement. The disappearance of the concrete cover in case of spalling makes the reinforcement bars unprotected. This leads to an increase of the heat transfer speed and subsequently to a further degradation of the concrete properties within the section accompanied by a rapid weakening of the steel rebars ( $c f$. sagging in case of rectangular tunnels as described in Chapter 4). Therefore, a sufficient protection could be obtained by applying a larger covering of the main reinforcement $(60-70 \mathrm{~mm})$ and adding extra mesh reinforcement (with a covering of about $20 \mathrm{~mm}) .{ }^{31}$

However, the most effective options for successful passive fire resistance, although not necessarily cost effective, are the incorporation of external insulation (usually thermal barriers, as shown in Fig. 5b, which keep the heating rate in the concrete at a low level) and the addition of polypropylene (PP) fibres in the mixture of concrete. There are many types of 
thermal barriers including insulation boards and coatings (e.g., cementitious ones ${ }^{58}$ ) as well as sprayed-on materials. In general, they reduce the heat flow to the substrate material limiting both the heating rate and the maximum developed temperatures at the concrete surface. A comprehensive overview concerning the use of thermal barriers for passive fire protection of concrete structures has been presented. ${ }^{37}$. There are several requirements that must be met during service condition and during fire. However, if the barrier fulfils these requirements, it constitutes the most effective solution, addressing both pore pressure and thermal stress spalling mechanisms, although the cost is much higher as compared to the incorporation of PP fibres.

The addition of PP fibres in the mixture of concrete is more recognized and widely used among the other possible solutions. The fibres melt at about $160^{\circ} \mathrm{C}$ and thus create channels and micro-cracks in which the water can be transported without developing high pore pressures, as has been verified through laboratory tests. ${ }^{59,60}$ Thus, as a result of melting of the PP fibres, an increased permeability is observed. Fire experiments have shown that the permeability of concrete with $1,5 \mathrm{~kg} / \mathrm{m}^{3}$ PP fibres can be up to four times greater than the permeability of concrete without fibres. ${ }^{61}$ Even though spalling may not occur in linings reinforced with PP fibres, dehydration of concrete requires the replacement of the damaged part of the lining. The part of the lining characterized by an adhesive tensile strength lower than 1,5 MPa must be replaced, while the depth of this part can be estimated from the distribution of the degree of hydration in the lining after a fire accident. ${ }^{47}$

Tests have shown ${ }^{62}$ that the matching of the grading curve and the type of aggregate have a particular significance besides the addition of PP fibres. ${ }^{62}$ The effectiveness of the PP fibres in the developed HSC mixes was tested using the fire curve of RABT/ ZTV for rail tunnels (Fig. 1). The concrete C55/67 with a PP fibre content of $2 \mathrm{~kg} / \mathrm{m}^{3}$ showed no spalling when flamed. To achieve comparable results, the $\mathrm{HSC}$ required $4 \mathrm{~kg} / \mathrm{m}^{3}$ of PP fibres. The UHSC, however, still showed surface damage even with much higher PP fibre content $\left(6 \mathrm{~kg} / \mathrm{m}^{3}\right)$, with spalling of more than $10 \mathrm{~mm}$. It should be noted that when using such quantities of fibres the workability of concrete may be affected.

Besides the size and the characteristics of the aggregates, the inter-aggregate spacing, the water-to-cement ratio of the mixture as well as the number, the length and the thickness of the fibres play a significant role concerning the effective prevention of spalling. ${ }^{63,64}$ Furthermore, the use of fibre combinations may improve the behaviour of a concrete member. Steel fibres, in combination with PP fibres, can limit the risk of propagating spalling by increasing the fracture energy of concrete, ${ }^{47,60}$ whereas its residual mechanical properties show a significant improvement. ${ }^{65}$ The use of steel fibre concrete is advantageous for segmental linings subjected to bending loading, instead of the usual reinforced concrete, ${ }^{62}$ which, however, is necessary in case of prominent compression for construction purposes. Moreover, the combination of PP with nylon fibres has shown a favourable effect on spalling mitigation. Specifically, better protection against spalling with lower fibre demand (up to three times less fibre content ${ }^{66}$ ) has been observed compared to that using only PP fibres. ${ }^{66,67}$

Concerning now the toxicity of the aforementioned protection measures, the use of inorganic materials for the thermal barriers would deter the production of smoke or toxic gases under high temperatures ${ }^{1}$ as long as they do not burn in contrast with organic ones. On the other hand, the combustion of PP fibres used in tunnel concrete mixes has indicated negligible toxicity. ${ }^{68}$

\begin{tabular}{|c|c|c|c|}
\hline No. & Method & Effectiveness & Comments \\
\hline 1 & Thermal barrier & Very effective & $\begin{array}{l}\text { Increases fire resistance by reducing heating rate and maximum } \\
\text { concrete/steel temperatures. Reduces both pore pressure and } \\
\text { thermal stress spalling, as well as compressive stress loss. High } \\
\text { cost. }\end{array}$ \\
\hline 2 & PP fibres & Very effective, even in HSC & $\begin{array}{l}\text { Addresses pore pressure spalling. Low-cost solution but may } \\
\text { not prevent spalling in expansive UHSC. Does not reduce tem- } \\
\text { peratures or strength loss, only pore pressures. Does not address } \\
\text { thermal stress spalling. Some strength reduction owing to air } \\
\text { bubbles created during mixing. More fibres are needed if con- } \\
\text { crete is heated under load and for stronger concrete. }\end{array}$ \\
\hline 3 & Choice of aggregate & $\begin{array}{l}\text { Low thermal expansion, low } \\
\text { porosity and small-size ag- } \\
\text { gregates are preferable }\end{array}$ & $\begin{array}{l}\text { Low thermal expansion reduces thermal stresses. A porous } \\
\text { aggregate, such as lightweight, could reduce spalling when dry } \\
\text { but promote it when wet. }\end{array}$ \\
\hline 4 & Moisture content control & Reduces vapour pressure & $\begin{array}{l}\text { Moisture content in tunnels is normally higher than in buildings } \\
\text { and more difficult to control. }\end{array}$ \\
\hline 5 & Compressive stress control & Reduces explosive pressure & Not economical with larger section sizes. \\
\hline 6 & Air-entraining agent & $\begin{array}{l}\text { Effective if moisture content } \\
\text { is low }\end{array}$ & $\begin{array}{l}\text { Can reduce strength. Could be problematic if concrete water is } \\
\text { saturated. }\end{array}$ \\
\hline 7 & Main reinforcement & Reduces spalling damage & Does not prevent spalling but limits the extent of damage. \\
\hline 8 & Supplementary reinforcement & Reduces spalling damage & Difficult to use in small and narrow sections. \\
\hline 9 & Steel fibres & Reduces spalling damage & $\begin{array}{l}\text { Explosive spalling may be more violent owing to extra strain } \\
\text { energy stored by steel fibres. }\end{array}$ \\
\hline 10 & Choice of section type/shape & $\begin{array}{l}\text { Thicker sections reduce } \\
\text { spalling damage }\end{array}$ & Important for I-beams and ribbed sections. \\
\hline
\end{tabular}

Table 1: Evaluation of preventive measures against explosive concrete spalling $21,23,36,37$ 
A summary of the various proposed prevention measures, especially against concrete explosive spalling, accompanied by a concise evaluation of their effectiveness, is described in Table 1. ${ }^{21,23,36,37}$ Finally, it should be noted that all these measures serve to retain the tunnel structure, but not to extinguish the fire.

\section{Conclusions}

An overview of some design aspects of concrete tunnel linings for fire safety has been presented. Initially, the thermal response was discussed. The special characteristics of tunnel fires have led to the development of specific fire curves with rapid temperature increase and high peak values. Transient heat transfer finite element analyses were performed to investigate the influence of each curve on the developed thermal profile at the depth of an unprotected reinforced concrete crosssection. It was shown that steep temperature gradients occur within the first few minutes, indicating the high risk for concrete spalling. The effect of fire on the concrete behaviour was described. Focus was given on explosive spalling, which occurred in many catastrophic tunnel fire incidents. The main features and mechanisms of spalling were presented. Finally, the available passive protection measures were examined, with the thermal barriers and the PP fibres being the most popular and effective solutions.

Despite the fact that extensive experimental and theoretical investigations have been carried out over the past decades to provide a deeper insight into the problem of concrete spalling, there are no prescriptive recommendations. Therefore, an effort should be made in the near future to depict this valuable knowledge into design standards. Furthermore, a systematic study should be performed in order to deduce design charts (or tabulated data) with respect to the structural fire performance of concrete members when thermal barriers and/or PP fibres (or fibre cocktails) are used, even for preliminary assessments. Additionally, a robust method for the calculation of fire resistance of protected concrete members against spalling should be established in combination with methods for the prediction of the explosive spalling risk. In spite of the lack of trustworthy practical tools, design assisted by test procedures can be used when spalling is expected. Finally, the development of the more sophisticated numerical procedures, which account for the thermal fluid-structural coupling in conjunction with the detailed multiphase modelling of concrete, should continue, since they can provide a better understanding of the developed thermal field and of the corresponding structural response of concrete tunnel linings during fire events.

\section{References}

[1] Beard A, Carvel R (eds). The Handbook of Tunnel Fire Safety. London, UK: Thomas Telford, 2005.

[2] Carvel RO. Fire size in tunnels. PhD Thesis, Division of Civil Engineering, School of the Built Environment, Heriot-Watt University, Riccarton, Edinburgh, 2004.

[3] Maevski IY. NCHRP Synthesis 415: Design Fires in Road Tunnels - A Synthesis of Highway Practice, Transportation Research Board: Washington, D.C., 2011

[4] Lönnermark A. On the characteristics of fires in tunnels. PhD Thesis, Department of Fire Safety Engineering, Institute of Technology, Lund University, Lund, 2005.

[5] Kirkland CJ. The fire in the Channel Tunnel, 2002 ITA Open Session: fire and life safety. Tunn. Undergr. Sp. Tech. 2002; 17: 129-132.

[6] Voeltzel A, Dix A. A comparative analysis of the Mont Blanc, Tauern and Gotthard tunnel fires. Routes/Roads. 2004; 324: 18-35.

[7] Leitner A. The fire catastrophe in the Tauern Tunnel: experience and conclusions for the Austrian guidelines. Tunn. Undergr. Sp. Tech. 2001; 16: 217-223.

[8] International Tunnelling Association (ITA) Guidelines for structural fire resistance for road tunnels. 2004.

[9] Ingason $\mathrm{H}$, Lönnermark $\mathrm{A}, \mathrm{Li} \quad \mathrm{YZ}$. Runehamar Tunnel Fire Tests. SP Technical Research Institute of Sweden, Fire Technology - SP Report 2011, 55: 2011.

[10] Rew C, Deaves D. Fire spread and flame length in ventilated tunnels, a model used in channel tunnel assessments. In: Proceedings of the 1st International Conference on Tunnel Fires and Escape From Tunnels, Lyon, France, 5-7 May 1999, pp. 397-406.

[11] Carvel RO, Beard AN, Jowitt PW. Fire spread between vehicles in tunnels: effects of tunnel size, longitudinal ventilation and vehicle spacing. Fire Technol. 2005; 41: 271-304.

[12] Ingason H, Li YZ. Model scale tunnel fire tests with longitudinal ventilation. Fire Safety $J$. 2010; 45: 371-384

[13] Blanchard E, Boulet P, Desanghere S, Cesmat E, Meyrand R, Garo JP, Vantelon JP. Experimental and numerical study of fire in a midscale test tunnel. Fire Safety J. 2012; 47: 18-31.

[14] Carvel RO, Beard AN, Jowitt PV. Fire size and fire spread in tunnels with longitudinal ventilation systems. J. Fire Sci. 2005; 23: 485-518.

[15] Li YZ, Lei B, Ingason H. Study of critical velocity and backlayering length in longitudi- nally ventilated tunnel fires. Fire Safety J. 2010; 45: $361-370$

[16] Collela F, Rein G, Verda V, Borchiellini R. Multiscale modeling of transient flows from fire and ventilation in long tunnels. Comput. Fluids. 2011; 51: 16-29.

[17] Wang HY. Numerical and theoretical evaluations of the propagation of smoke and fire in a full-scale tunnel. Fire Safety J. 2012; 49: 10-21.

[18] Cheong MK, Spearpoint MJ, Fleischmann CM. Calibrating an FDS simulation of goodsvehicle fire growth in a tunnel using the Runehamar experiment. J. Fire Protect. Eng. 2009; 19: 177-196.

[19] Xiaojun C. Simulation of temperature and smoke distribution of a tunnel fire based on modifications of multi-layer zone model. Tunn Undergr. Space Tech. 2008; 23: 75-79.

[20] Li YZ, Ingason H. The maximum ceiling gas temperature in a large tunnel fire. Fire Safety J. 2012; 48: 38-48.

[21] Khoury GA. Effect of fire on concrete and concrete structures. Prog. Struct. Eng. Mater. 2000; 2: 429-447.

[22] Taillefer N, Carlotti P, Lemerle C, Avenel R, Larive C, Pimienta P. Ten years of increased hydrocarbon temperature curves in French tunnels. Fire Technol. 2013; 49: 531-549.

[23] Bailey CG, Khoury GA. Performance of concrete structures in fire. Camberley, Surrey, UK: MPA - The Concrete Centre: 2011.

[24] International Organization for Standardization (ISO). ISO 834: Fire resistance tests - elements of building construction - Part 1 : General requirements. 1999.

[25] European Committee for Standardization (CEN). Eurocode 1: Actions on structures Part 1-2: General actions - Actions on structures exposed to fire. ENV 1991-1-2, 2002.

[26] ASTM International. ASTM E119: Standard methods of fire tests of building construction and materials. 2001.

[27] Ministère de l'Equipement. Instruction technique annexée à la Circulaire interministérielle no 2000-63 du 25 Aout 2000 relative à la sécurité dans les tunnels du réseau routier français. Bulletin officiel du Ministère de l'Equipement nº 20000-6 du 0109 2000, Paris, , 2000.

[28] Lacroix D, Haack A. PIARC design criteria for resistance to fire for road tunnel structures. Routes/Roads. 2004; 324: 64-71.

[29] Dassault Systèmes. Abaqus 6.10 - Analysis User's Manual. 2010.

[30] European Committee for Standardization (CEN). Eurocode 2: Design of concrete structures - Part 1-2: General rules - Structural fire design. ENV 1992-1-2, 2002.

[31] Boström L, Larsen CK. Concrete for tunnel linings exposed to severe fire exposure. Fire Technol. 2006; 42: 351-362.

[32] Bažant ZP, Kaplan MF. Concrete at High Temperatures: Material Properties and Mathematical Models. Harlow, Essex, UK: Longman Group Limited, 1996.

[33] International Federation for Structural Concrete (FIB). Fire design of concrete 
structures - materials, structures and modelling. Bulletin 38, 2007

[34] International Federation for Structural Concrete (FIB). Fire design of concrete structures - structural behaviour and assessment. Bulletin 46, 2008.

[35] Ulm F-J, Coussy O, Bažant ZP. The "Chunnel" fire. I: Chemoplastic softening in rapidly heated concrete. J. Eng. Mech. 1999; 125(3): 272-282.

[36] Khoury GA, Anderberg Y. Concrete spalling review. Report submitted to the Swedish National Road Administration, 2000.

[37] Khoury GA. Passive fire protection of concrete structures. Struct. Buil. 2008; 161: 135-145.

[38] Zeiml M, Lackner R, Mang HA. Experimental insight into spalling behavior of concrete tunnel linings under fire loading. Acta Geothechnica. 2008; 3: 295-308.

[39] Hertz KD, Limits of spalling of fire-exposed concrete. Fire Safety J. 2003; 38: 103-116.

[40] Ali F. Is high strength concrete more susceptible to explosive spalling than normal strength concrete in fire? Fire Mater. 2002; 26: 127-130.

[41] Efectis Nederland BV. Fire testing procedure for concrete tunnel linings. 2008.

[42] Gawin D, Pesavento F, Schrefler BA. What physical phenomena can be neglected when modelling concrete at high temperature? A comparative study. Part 1: physical phenomena and mathematical model. Int. J. Solids and Struct. 2011; 48: 1927-1944.

[43] Gawin D, Pesavento F, Schrefler BA. What physical phenomena can be neglected when modelling concrete at high temperature? A comparative study. Part 2: comparison between models. Int. J. Solids and Struct. 2011; 48: 1945-1961.

[44] El-Arabi IA, Duddeck H, Ahrens $\mathrm{H}$. Structural analysis for tunnels exposed to fire temperatures. Tunn. Undergr. Space Technol. 1992; 7(1): 19-24.

[45] Deeny S, Stratford T, Dhakal RP, Moss PJ, Buchanan AH. Spalling of concrete: Implications for structural performance in fire. In: Proceedings of the 20th Australasian Conference on Mechanics of Structures and Materials, Toowoomba, Australia, 2008.
[46] Ulm F-J, Acker P, Lévy M. The "Chunnel" fire. II: analysis of concrete damage. J. Eng. Mech. 1999; 125(3): 283-289.

[47] Pichler C, Lackner R, Mang HA. Safety assessment of concrete tunnel linings under fire load. J. Struct. Eng. 2006; 132(6): 961-969.

[48] Caner A, Zlatanic S, Munfah N. Structural fire performance of concrete and shotcrete tunnel liners. J. Struct. Eng. 2005; 131(12): 1920-1925.

[49] Savov K, Lackner R, Mang HA. Stability assessment of shallow tunnels subjected to fire load. Fire Safety J. 2005; 40: 745-763.

[50] Zeiml M, Lackner R, Pesavento F, Schrefler BA. Thermo-hydro-chemical couplings considered in safety assessment of shallow tunnels subjected to fire load. Fire Safety J. 2008; 43: 83-95.

[51] Ring T, Zeiml M, Lackner R. Underground structures under fire - From material modeling of concrete under combined thermal and mechanical loading to structural safety assessment. Computational Structural Engineering, Yuan Y, Cui JZ, Mang HA (eds), Dordrecht: Springer, 2009; pp. 71-78.

[52] Schrefler BA, Codina R, Pesavento F, Principe J. Thermal coupling of fluid flow and structural response of a tunnel induced by fire. Int. J. Numer. Meth. Eng. 2011; 87: 361-385.

[53] Schrefler BA, Brunello P, Gawin D, Majorana $\mathrm{CE}$, Pesavento F. Concrete at high temperature with application to tunnel fire. Comput. Mech. 2002; 29: 43-51.

[54] Felicetti R. Assessment methods of fire damages in concrete tunnel linings. Fire Technol. 2013; 49: 509-529.

[55] Yan Z-g, Zhu H-h, Woody Ju J, Ding W-q. Full-scale fire tests of RC metro shield TBM tunnel linings. Constr. Buil. Mater. 2012; 36: 484-494.

[56] Yan Z-g, Zhu H-h, Woody Ju J. Behavior of reinforced concrete and steel fiber reinforced concrete shield TBM tunnel linings exposed to high temperatures. Constr. Buil. Mater. 2013; 38 610-618.

[57] Carvel R, Colella F, Rein G. Using active systems to control tunnel fire events. Eng. Comput. Mech. 2012; 165(EM4): 245-252.

[58] Kim J-HJ, Lim YM, Won JP, Park HG. Fire resistant behavior of newly developed bottom-ash-based cementitious coating applied concrete tunnel lining under RABT fire loading. Constr. Buil. Mater. 2010; 24: 1984-1994.

[59] Phan LT. Pore pressure and explosive spalling in concrete. Mater. Struct.. 2008; 41: 1623-1632.

[60] Bangi MR, Horiguchi T. Pore pressure development in hybrid fibre-reinforced high strength concrete at elevated temperatures. Cement and Concrete Res. 2011; 41: 1150-1156.

[61] Zeiml M, Leithner D, Lackner R, Mang HA. How do polypropylene fibers improve the spalling behavior of in-situ concrete? Cement Concrete Res. 2006; 36: 929-942.

[62] Gipperich C, Schaab A, Otremba H-J Material technology developments in shield tunnelling - annular gap mortar, high-strength concrete and fire-protection concrete. Geomech. Tunn. 2010; 3(3): 283-294.

[63] Heo Y-S, Sanjayan JG, Han C-G, Han M-C Relationship between inter-aggregate spacing and the optimum fiber length for spalling protection of concrete in fire. Cement Concrete Res. 2012; 42: 549-557.

[64] Bilodeau A, Kodur VKR, Hoff GC Optimization of the type and amount of polypropylene fibres for preventing the spalling of lightweight concrete subjected to hydrocarbon fire. Cement \& Concrete Comp. 2004; 26: 163-174.

[65] Pliya P, Beaucour A-L, Noumowé A Contribution of cocktail of polypropylene and steel fibres in improving the behaviour of high strength concrete subjected to high temperature. Constr. Build. Mater. 2011; 25: 1926-1934.

[66] Heo Y-S, Sanjayan JG, Han C-G, Han M-C Synergistic effect of combined fibers for spalling protection of concrete in fire. Cement Concrete Res. 2010; 40: 1547-1554.

[67] Lee G, Han D, Han M-C, Han C-G, Son $\mathrm{H}-\mathrm{J}$. Combining polypropylene and nylon fibers to optimize fiber addition for spalling protection of high-strength concrete. Constr. Build. Mater. 2012; 34: 313-320.

[68] Khoury GA. Concrete spalling assessment methodologies and polypropylene fibre toxicity analysis in tunnel fires. Struct. Concr. 2008; 9(1): 11-18.

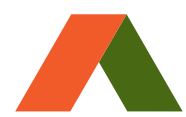

Being a Member of IABSE brings you together...

\author{
Young Engineers, \\ meet eminent practitioners, make contact with other enthusiastic engineers \\ and become part of a group committed to the furtherance of their subject.
}

www.iabse.org ..tell your colleague. 